\title{
Numerical Investigation on Nonlinear Dynamic Responses of a Towed Vessel in Calm Water
}

\section{Bo Woo Nam}

Department of Naval Architecture and Ocean Engineering, Seoul National University, Seoul 08826, Korea; bwnam@snu.ac.kr; Tel.: +82-2-880-7324; Fax: +82-2-880-9298

Received: 28 February 2020; Accepted: 18 March 2020; Published: 20 March 2020

\begin{abstract}
In this study, we numerically investigated the nonlinear dynamic responses of an autonomous towing system where a vessel is passively towed by a tug via a towline. A three-degrees-of-freedom maneuvering mathematical model is utilized to describe the nonlinear dynamics of the towed vessel in calm sea. The hydrodynamic force acting on the towed vessel is modelled as a modular-type hull force model, which includes linear and nonlinear (third order) damping forces in sway and yawing directions. The towline force is simply modeled as a linear spring. First, the motion responses of a towing system, showing large sway-yaw coupled motions due to unstable towing characteristics, are studied by applying phase plane analysis. For the validation of the present numerical method, the simulation results are directly compared with the model test data. Then, simulation parameters, such as towing speed, initial positions and hull force coefficients, are changed and their resulting limit cycles are investigated. Finally, the effects of towline and tug motion are discussed based on the simulation results. It is found that the dynamic characteristics of the towed vessel come closer to being chaotic due to the nonlinear stiffness effect of the towline and tug motion effect.
\end{abstract}

Keywords: towing stability; towed vessel; nonlinear dynamics; towline; limit cycle

\section{Introduction}

In towing operations, vessels with no self-propulsion, such as transportation barges, can be towed by single or multiple tug systems. In this case, if the towing stability conditions are not satisfied, the towed vessel may undergo a transition from stable towing to an unstable slewing phenomenon, whereby the towed vessel experiences large sway and yaw coupled motion, such as fishtailing. Due to the fact that the unstable slewing motion of the towed vessel can result in collision with sea-going vessels or moor installations, it is very important to investigate towing stability prior to towing operations. The stability of the towed vessel is mainly influenced by parameters such as its hull geometry, towing conditions, towline and tug system [1-4].

Research on towing stability started with an analysis based on characteristics equations derived from mathematical models. Strandhagen et al. [1], Abkowitz [2], Bernitsas and Kekerdis [3] derived a characteristic equation for determining the stability of a towed vessel in calm sea. They explained that the towing stability is ensured only if two conditions are met. The first one is the restoring moment condition, which means that the towed vessel is hydrodynamically stable if the restoring moment, due to the lateral hydrodynamic force, is larger than the hydrodynamic yawing moment. The second condition is the minimum resistance condition, meaning that the towline tension corresponding to ship resistance should be larger than a critical value. In general, when the first condition is not satisfied, single or multiple rudders can be utilized as a passive control device for the towing system, in order to change the hydrodynamic characteristics of the hull. The introduction of rudders, which 
are normally installed at the rear of the towed vessel, may increase the restoring moments, due to the lateral hydrodynamic force when the drift angle occurs.

Practically, model tests can be performed to check the stability characteristics of the towed vessel. By using a scaled model under the dynamic similitude law, these tests can provide information about the overall behavior of the towed vessel under various conditions. Latorre [5] showed a series of model test results for determining the stability of a towed ship, discussing the scale effect. He pointed out that special care is needed for the application of model test results to real ship situations, because the model scale result gives more optimistic predictions than the real scale values. Yasukawa et al. [6] presented the results of towing experiments with single and dual barges, showing the slewing motion phenomenon of the barge. Hong et al. [7] carried out captive and towing model tests for a transportation barge, with focus on the scale and wave effects on towing stability.

Recently, the direct numerical simulation method has also been widely used to evaluate the towing performance. In this case, the numerical model is normally based on the maneuvering equation of the towed vessel. The towing simulation can give good predictions for various operation conditions, provided that the input hydrodynamic coefficients are accurately estimated. Yasukawa et al. [6] presented simulation results based on the MMG (maneuvering modeling group) model, comparing them with model test data. Fitriadhy and Yasukawa [8] and Fitriadhy et al. [9] presented towing stability results, considering the wind effects and numerical simulation results based on the MMG model. Fitriadhy and Yasukawa [10] proposed a numerical model for the course stability of a towed ship, that is coupled to a tow ship through a towline. Nam et al. [11] compared a cross-flow model [12] and the MMG model for the towing simulation of barges in calm water. They found a reasonable agreement between these models for the towing simulation. Nam et al. [13] studied the towing characteristics of a barge under various wind conditions. They applied the wind coefficients from CFD calculations. Discussions were made on the effects of the wind direction and skeg on the slewing motion. Fitriadhy et al. [14] presented a numerical simulation of the turning operation, considering the interaction effect between the tug and towed ship. They also suggested the slack towline criteria and validated the theoretical approaches qualitatively, by comparing the model test results.

In this study, nonlinear dynamic responses of a towing system are numerically investigated, based on a three degree-of-freedom maneuvering model. The hydrodynamic force acting on the towed vessel is modelled as an MMG-type hull force model, while the towline force is simply modeled as a linear spring. The dynamic motion responses of the towed vessel are analyzed by using phase plane analysis. Phase trajectories are presented to show the dynamic characteristics of the autonomous towing system. In addition, a series of numerical simulations are carried out to investigate the effect of various simulation parameters on their resulting limit cycles. Additionally, discussions are made on the effects of towline and tug motion, based on the simulation results.

\section{Mathematical Model}

When a vessel is passively towed by a tug via a towline, it can be exposed to the possibility of unstable slewing motion, which is a periodic fishtailing motion of the towed vessel. The towed vessel in calm sea may normally experience large horizontal motion responses of surge, sway and yaw. In this case, the slewing motion of the towed vessel has long natural periods, due to small restoring forces, so the memory effects from free-surface are considerably small. Therefore, in this study, a three-degrees-of-freedom maneuvering mathematical model is utilized to describe the nonlinear dynamics of the towed vessel in calm sea. Two different coordinate systems are introduced, shown in Figure 1; one is the space-fixed coordinate system (O-XYZ), and the other is the vessel-fixed coordinate system (o-xyz). The positive $x-, y$ - and $z$-axes point in the forward, starboard and downward directions, respectively. 


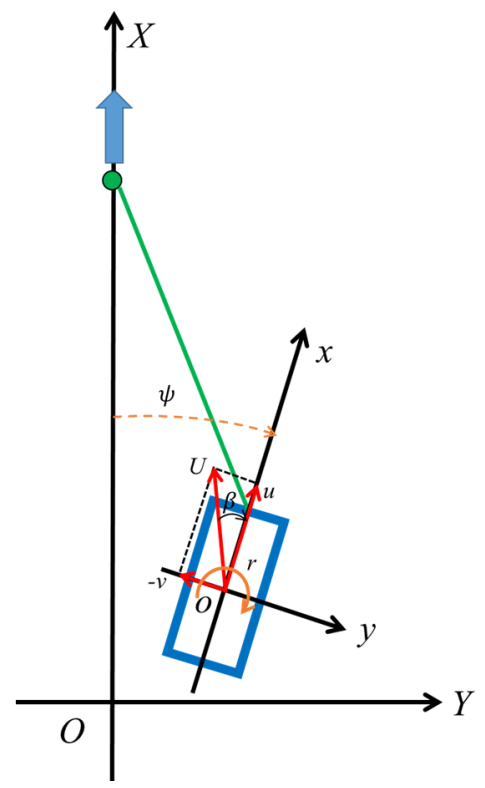

Figure 1. Coordinate system.

The state vector of this system is defined as $\mathbf{x}=\{u, v, r, x, y, \psi\}^{T}$. Here, $u, v, r$ are surge velocity, sway velocity and yaw rate of the towed vessel in the vessel-fixed coordinate system, respectively. Moreover, $x, y, \psi$ are surge displacement, sway displacement and yaw angle of the towed vessel in the space-fixed coordinate system, respectively. The dynamical system of the towed vessel can be represented by the following state equations:

$$
\dot{\mathbf{x}}=\mathbf{F}(\mathbf{x})=\left\{f_{1}(\mathbf{x}), f_{2}(\mathbf{x}), f_{3}(\mathbf{x}), \ldots \ldots, f_{6}(\mathbf{x})\right\}^{T}
$$

where

$$
\begin{gathered}
f_{1}(\mathbf{x})=\left\{-\left(m+m_{y}\right) v r+\frac{1}{2} \rho L d U^{2}\left(X_{\beta \beta} \beta^{2}+X_{\beta r} \beta r+X_{r r} r^{2}\right)-\frac{1}{2} \rho L d u^{2} X_{u u}+F_{x}^{T}\right\} /\left(m+m_{x}\right) \\
f_{2}(\mathbf{x})=\left\{-\left(m+m_{x}\right) u r+\frac{1}{2} \rho L d U^{2}\left(Y_{\beta} \beta+Y_{r} r+Y_{\beta \beta \beta} \beta^{3}+Y_{\beta \beta r} \beta^{2} r+Y_{\beta r r} \beta r^{2}+Y_{r r r} r^{3}\right)+F_{y}^{T}\right\} /\left(m+m_{y}\right) \\
f_{3}(\mathbf{x})=\left\{\frac{1}{2} \rho L^{2} d U^{2}\left(N_{\beta} \beta+N_{r} r+N_{\beta \beta \beta} \beta^{3}+N_{\beta \beta r} \beta^{2} r+N_{\beta r r} \beta r^{2}+N_{r r r} r^{3}\right)+M_{z}^{T}\right\} /\left(I_{z z}+J_{z z}\right) \\
f_{4}(\mathbf{x})=u \cos \psi-v \sin \psi \\
f_{5}(\mathbf{x})=u \sin \psi+v \cos \psi \\
f_{6}(\mathbf{x})=r
\end{gathered}
$$

Here, $m$ and $I_{z z}$ denote the mass and yaw moment of inertia of the towed vessel, respectively. The parameters $m_{x}$ and $m_{y}$ are added masses in surge and sway, respectively. $J_{z z}$ is the added yaw moment of inertia; $\rho$ is water density; $L$ and $d$ are the length and draft of the towed vessel, respectively; $U$ is the total speed of the towed vessel, defined as $\sqrt{u^{2}+v^{2}} ; \beta$ is a drift angle, which can be defined as $\tan ^{-1}(-v / U) ; X_{\beta \beta}, X_{\beta r}$ and $X_{r r}$, are the hydrodynamic force coefficients regarding longitudinal force in surge direction; $Y_{\beta}, Y_{r}, Y_{\beta \beta \beta}, Y_{\beta \beta r}, Y_{\beta r r}$ and $Y_{r r r}$ are the hydrodynamic force coefficients of lateral force based on a 3rd-order polynomial model [6]; similarly, $N_{\beta}, N_{r}, N_{\beta \beta \beta}, N_{\beta \beta r}, N_{\beta r r}$ and $N_{r r r}$ are the hydrodynamic force coefficients of lateral force, based on the 3rd-order polynomial model. The dynamic responses of the towed vessel are obviously affected by these hydrodynamic coefficients of the hull. Finally, $F_{x}^{T}, F_{y}^{T}$ and $M_{z}^{T}$ are the towline forces and moment. During a normal towing operation, the axial stiffness of the towline plays a dominant role, and it can be assumed that towline 
behavior is in a linear regime. Thus, in this study, a simple spring model can be introduced without considering any nonlinear and damping effects in the towline. It can be concluded that the main damping and nonlinearity for the total towing system come from hydrodynamic forces acting on the hull. Due to the fact that the external towline forces are functions of the vessel displacement, but not of time, the motion equations under discussion here are nonlinear and autonomous. In this study, based on the above-mentioned mathematical model, numerical simulations were carried out for a towed barge with length $(L)$ of $1.219 \mathrm{~m}$, breadth $(B)$ of $0.213 \mathrm{~m}$ and draft $(d)$ of $0.0548 \mathrm{~m}$ in a $1 / 50$ model scale, which was introduced by Yasukawa et al. [6] The principal particulars and the hydrodynamic coefficients can be found in [6].

\section{Nonlinear Dynamics of a Towed Vessel}

\subsection{Dynamic Motion Responses of a Towing System}

The first case examined here is the motion responses of a towing system, in which a vessel is tugged though a towline, showing large sway-yaw coupled motions due to unstable towing characteristics. The time histories of the towed vessel motion and towline tension are presented in Figure 2. For the validation of the present numerical method, the simulation results are directly compared with the model test data of Yasukawa et al. [6]. In this case, it is assumed that the towing operation is performed at a constant towing speed $(V)$, following a straight path. Here, the towing speed corresponds to 0.145 as the Froude number which is defined as $\mathrm{Fn}=V / \sqrt{g L}$. No tug control effects are taken into account. Thus, the tug can be assumed as an imaginary towing point, which is constantly moving. It is to be noted that the experimental data are only available up to approximately $60 \mathrm{~s}$ in model scale, due to the limitation of basin size. Therefore, only $4-5$ periods of slewing motion can be observed. As shown in the figures, large oscillatory yawing motion is clearly observed in terms of yaw angle and yaw rate. In this case, the slewing motion period is approximately $22 \mathrm{~s}$ in model scale, and the maximum yawing angle is approximately $40^{\circ}$. In the case of towline tension, high tension peaks occur every $11 \mathrm{~s}$, half of the slewing motion period, because the towline is periodically stretched when the towed vessel changes its heading at both lateral end positions of the slewing trajectory. Due to these fishtailing motions of the towed vessel, the yaw rate and tension time histories clearly show highly nonlinear characteristics with higher harmonic components.

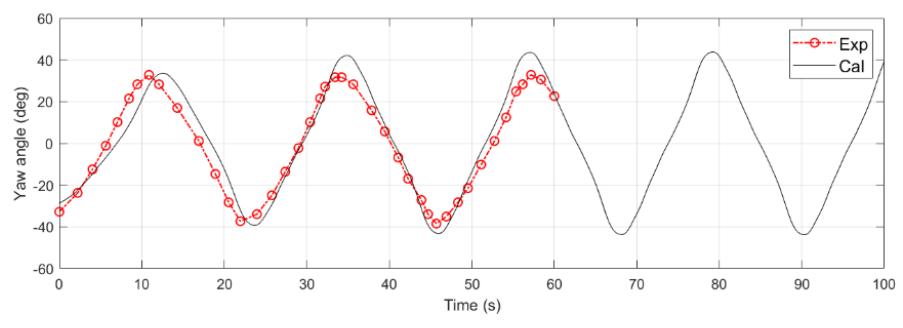

(a) Yaw angle

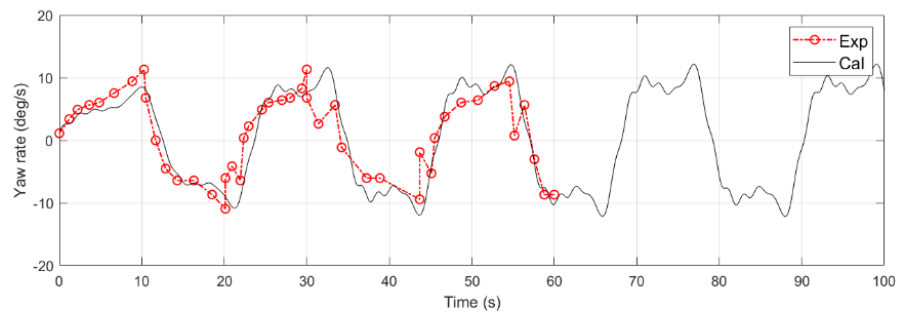

(b) Yaw rate

Figure 2. Cont. 


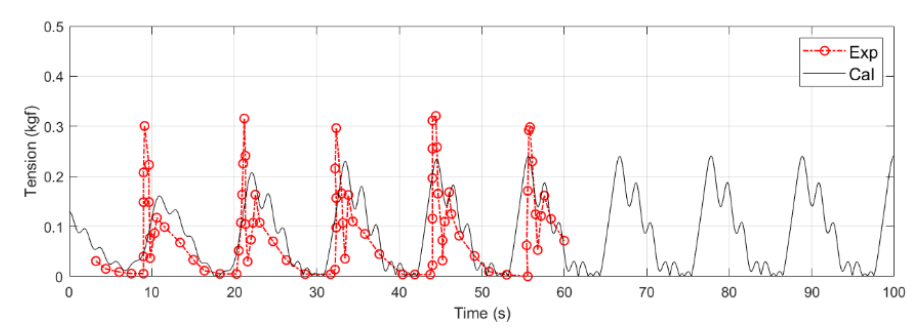

(c) Towline tension

Figure 2. Time histories of the towed vessel motion and towline tension.

To reveal the dynamic characteristics of this towing system, four phase trajectories, which are based on the velocity and motion variables of the towed vessel, are shown in Figure 3. In each figure, the blue dashed line denotes the phase trajectory from 20 to $70 \mathrm{~s}$, which corresponds to the initial transient motion response of the towed vessel. The black solid line represents the phase trajectory from 70 to $500 \mathrm{~s}$, where the steady periodic motions follow the closed oscillation. Therefore, this periodic phase trajectory is 'a single stable limit cycle' of the dynamic system under discussion here. It can be stated that after a short transient response depending on the initial conditions, the dynamic states of the towed vessel are quickly attracted to the limit cycle. When considering the $(\mathrm{u}, \mathrm{v})$ and $(\mathrm{u}, \mathrm{r})$ projections of the system's state space, the phase trajectories appear to have the shape of a butterfly. This is because the lateral velocity $(\mathrm{v})$ and yaw rate $(\mathrm{r})$ have almost twice the oscillation period of surge velocity $(\mathrm{u})$. As shown in Figure 1, these surge oscillations are also directly related to the towline tension responses. It can be seen that the phase trajectories of sway-yaw velocities $(\mathrm{v}, \mathrm{r})$ and motions $(y, \psi)$ constitute closed circular curves, which look like skewed ellipses. This indicates that the sway and yaw motion have the same periods of slewing motion. Figure 4 shows the three-dimensional phase trajectories of the towed vessel with the velocity variables (u-v-r). In this figure, the whole dynamic structure is more clearly shown. In the three-dimensional phase space, it can be seen that no intersections are found in the limit cycle, which means that only one path is determined at a certain state on the limit cycle.

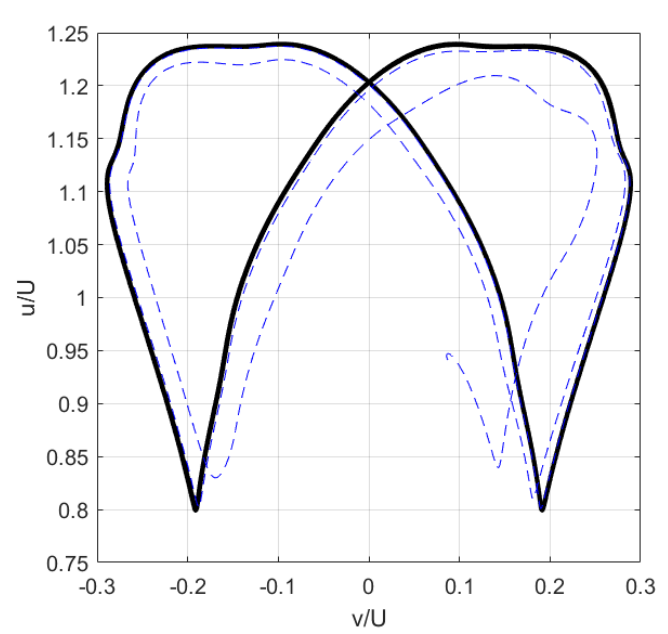

(a) $(\mathrm{u}, \mathrm{v})$ phase trajectory

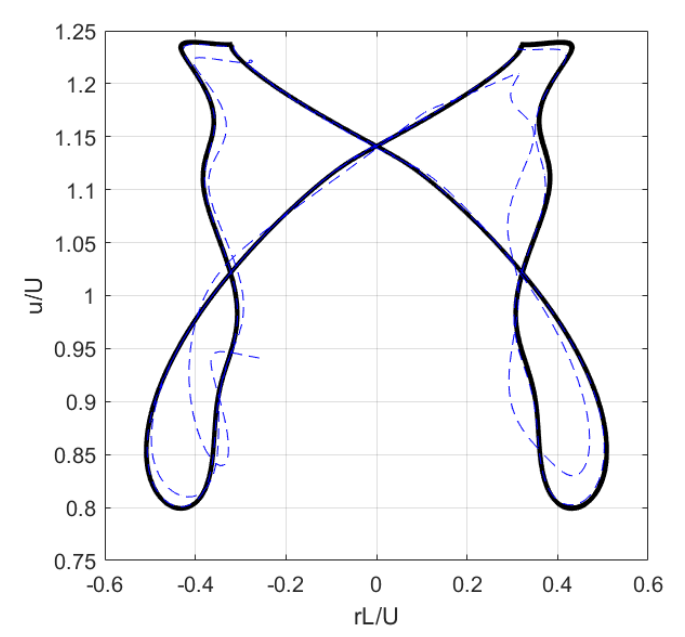

(b) $(u, r)$ phase trajectory

Figure 3. Cont. 


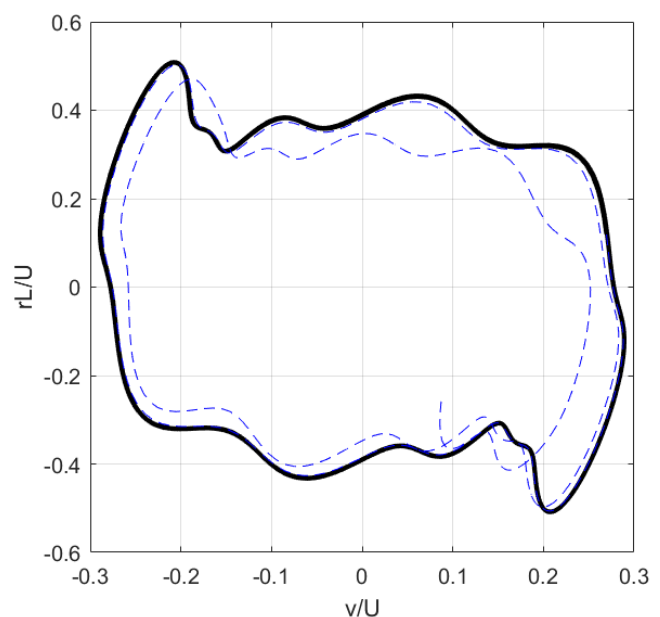

(c) $(\mathrm{v}, \mathrm{r})$ phase trajectory

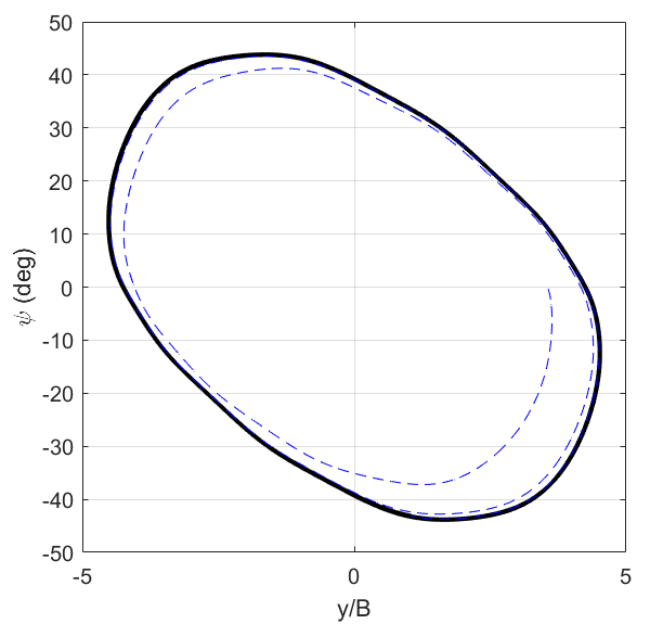

(d) $(y, \psi)$ phase trajectory

Figure 3. Phase trajectories of the towed vessel (blue dashed: 20-70 s, black solid: 70-500 s).

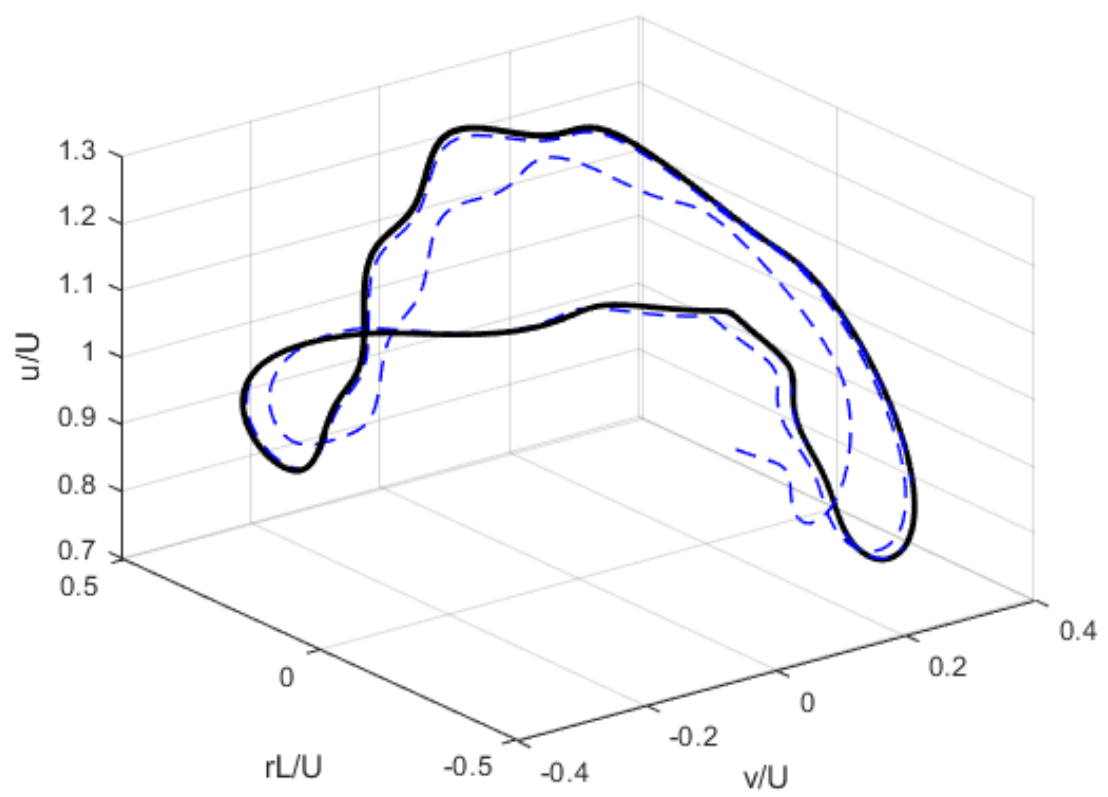

Figure 4. Phase trajectories of the towed vessel in the three-dimensional phase space (blue dashed: 20-70 s, black solid: 70-500 s).

\subsection{Simulation Parameters and Limit Cycle}

The dynamic characteristics of the towed vessel can be affected by various simulation parameters. Some critical parameters can change the resulting limit cycle of the towed vessel, while others mainly affect the transient response, without changing the limit cycle. For example, the transient response would be affected by the initial conditions of the towed vessel. However, the stable limit cycle of the dynamic system should be the same, regardless of the initial conditions. To check the characteristics of the limit cycle for the towing system under discussion here, various phase trajectories with different initial conditions are suggested in Figure 5. Even though the initial conditions are quite different in terms of the lateral position $\left(y_{0}\right)$ and yaw angle $\left(p s i_{0}\right)$ of the towed vessel, it can be clearly observed that the dynamic states of the towed vessel are quickly attracted to the same limit cycle within a short time period. These results demonstrate that the dynamic system of the towed vessel has a stable limit cycle. 


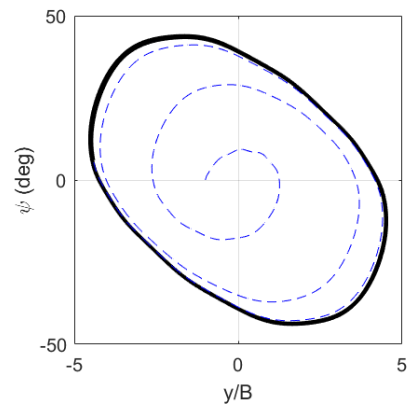

(a) $y_{0} / B=-1.0, \psi_{0}=0.0 \mathrm{deg}$

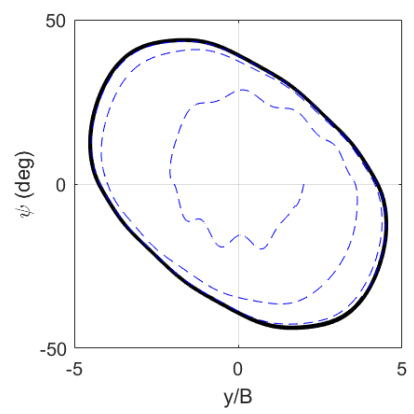

(d) $y_{0} / B=2.0, \psi_{0}=0.0 \mathrm{deg}$

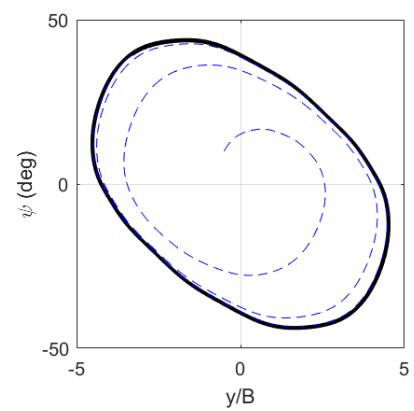

(b) $y_{0} / B=-0.5, \psi_{0}=10.0 \mathrm{deg}$

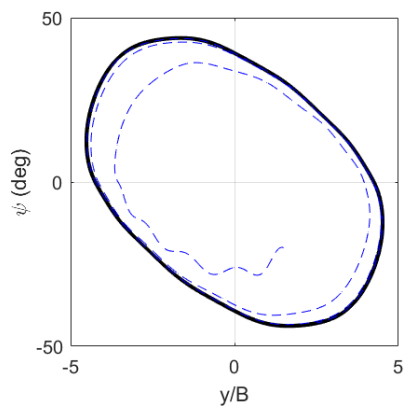

(e) $y_{0} / B=1.5, \psi_{0}=-20.0 \mathrm{deg}$

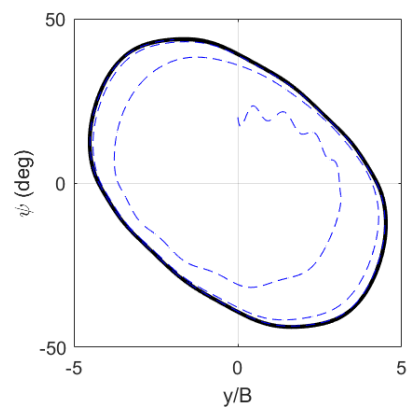

(c) $y_{0} / B=0.0, \psi_{0}=20.0 \mathrm{deg}$

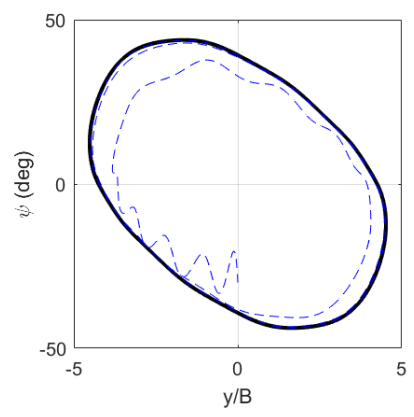

(f) $y_{0} / B=0.0, \psi_{0}=-30.0 \mathrm{deg}$

Figure 5. Phase trajectories of the towed vessel with different initial conditions $\left(\mathrm{Fn}=0.145, L_{T} / L=1.0\right)$.

Towing speed is another important control parameter of the towing operation, which affects the limiting cycle. Figure 6 compares three phase trajectories under different towing speed conditions. In this figure, only the limit cycles from periodic motion trajectories are plotted together. As the towing speed increases, the resistance of the towed vessel also increases, thereby increasing the towline tension. It is known that the stable towing requires sufficient towline tension [1-3]. This means that a low towing speed makes the towing dynamics more unstable. Conversely, an increase of towing speed can improve the towing characteristics. As shown in the figures, the shapes and sizes of the phase trajectories are very similar, regardless of the towing speed. Since the velocity variables are normalized by the towing speed, similar trajectory sizes mean that the velocity responses of the towed vessel are linearly increased with the towing speed. Under the non-dimensional phase space, it can be confirmed that the limit cycles are not greatly changed according to the towing speed. Therefore, the general nonlinear dynamic characteristics of the towed vessel can be discussed, with normalized phase planes. 


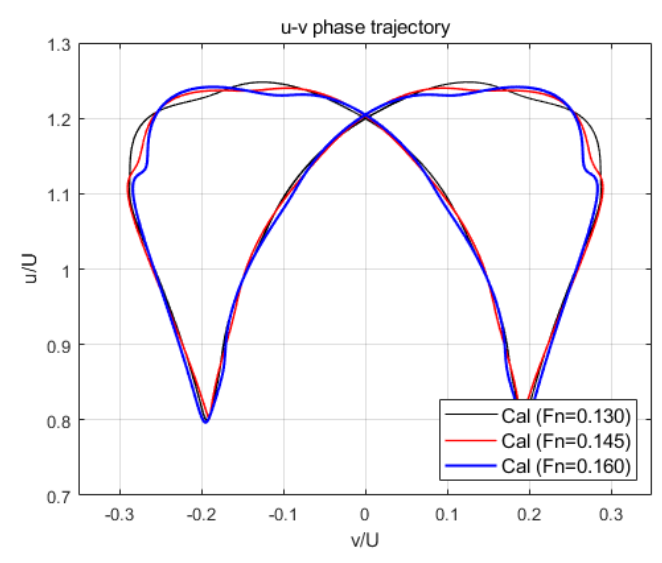

(a) (u, v) phase trajectory

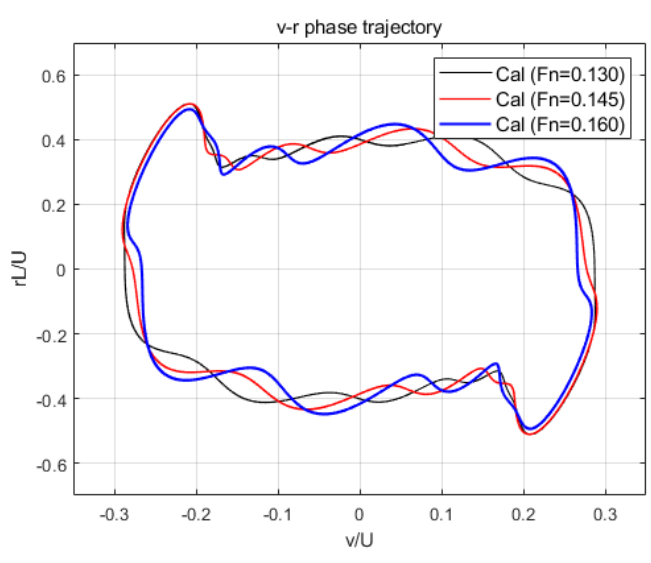

(b) $(\mathrm{v}, \mathrm{r})$ phase trajectory

Figure 6. Phase trajectories of the towed vessel under various towing speed conditions $\left(L_{T} / L=1.0\right)$.

Figure 7 shows the effects of hull hydrodynamic force coefficients on towing phase trajectories. In the first row, the simulation results with variations of linear yawing moment coefficient $\left(N_{\beta}\right)$ are presented. It is known that towing stability is ensured when the restoring moment due to lateral force is bigger than yawing moment [1-3]. Therefore, as the yawing moment decreases, better towing stability may be expected. As shown in the figures, the phase trajectories become smaller with the decrease of the yawing moment. In the second row of Figure 7, the simulation results with resistance $\left(X_{u u}\right)$ variation are presented. The resistances are increased by $20 \%$ and $40 \%$. As the resistance increases, the towline tension becomes stronger, improving towing stability. Thus, it can be observed that the increase of resistance makes the phase trajectories smaller. Figure 8 shows the effect of numerical models on the dynamics of the towed vessel. Here, two numerical models are taken into account. The original nonlinear MMG model includes higher-order damping force terms while the linearized MMG model only includes linear damping terms for hull force modeling. As shown in the figures, as the linear model is used, the phase trajectories become slightly larger than those of the nonlinear model. This confirms that the linear model generates lower damping forces, so that the motion responses of the towed vessel become larger.
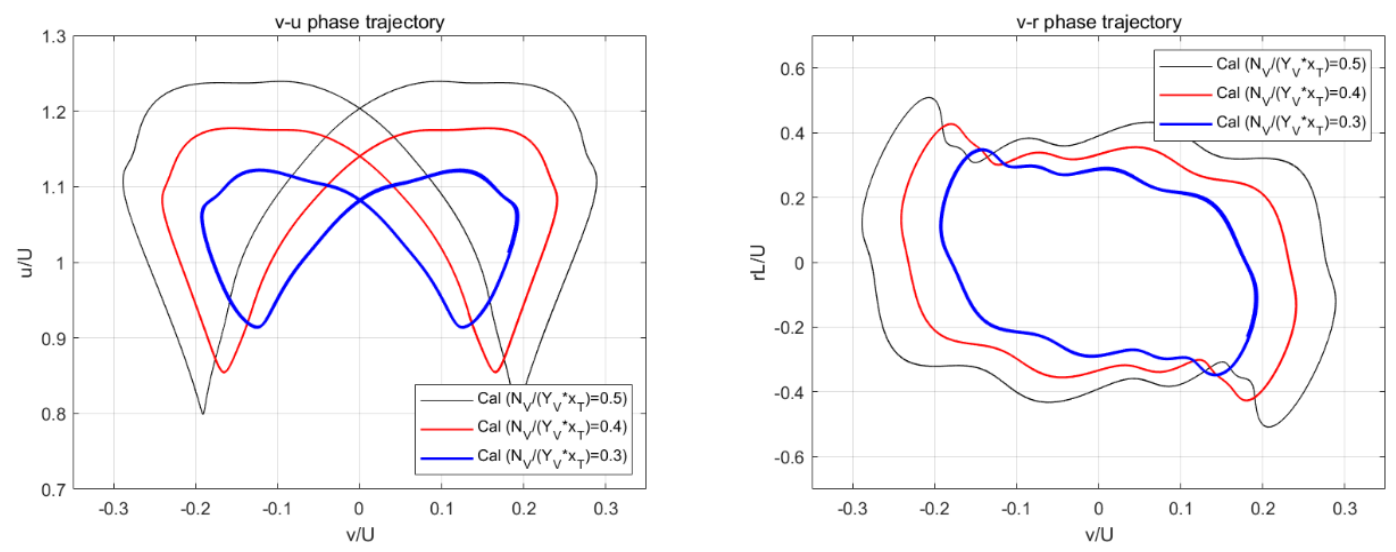

(a) Yawing moment $\left(N_{\beta}\right)$ variation

Figure 7. Cont. 

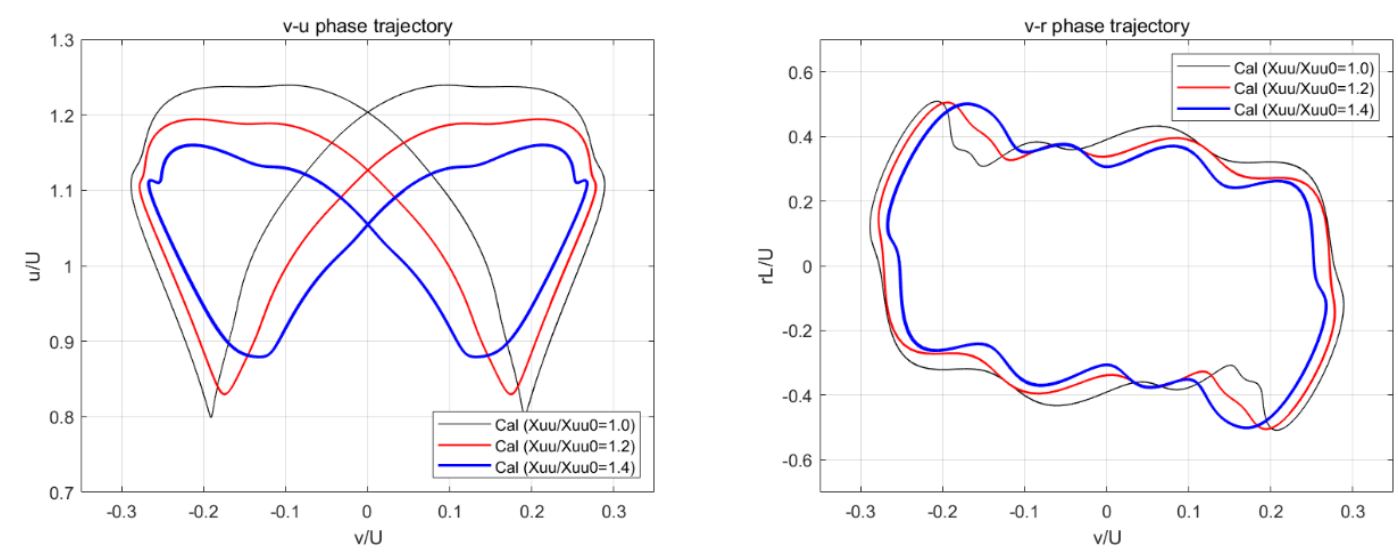

(b) Resistance $\left(X_{u u}\right)$ variation

Figure 7. Phase trajectories of the towed vessel with hull force variations $\left(L_{T} / L=1.0\right)$.

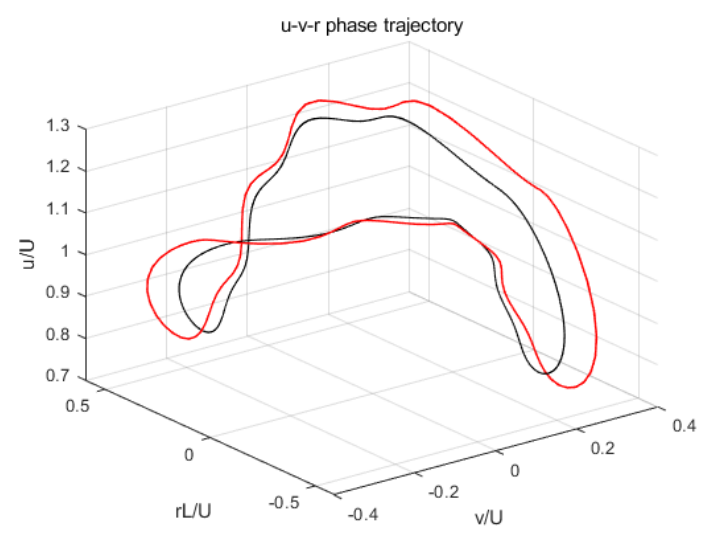

(a) $(\mathrm{u}, \mathrm{v}, \mathrm{r})$ phase trajectory

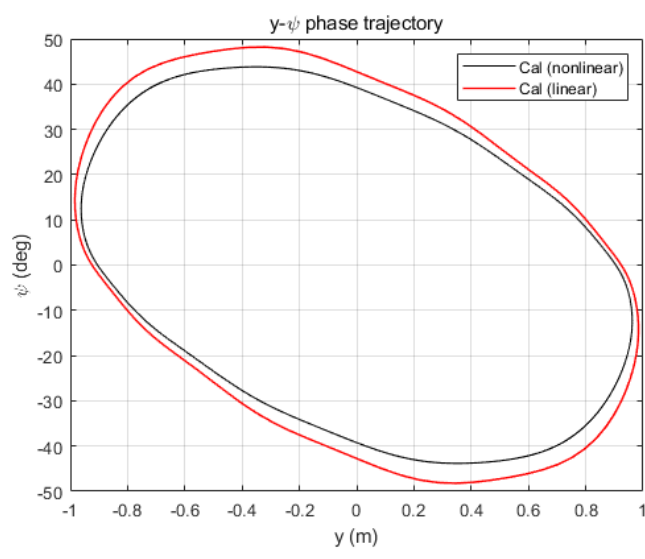

(b) $(y, \psi)$ phase trajectory

Figure 8. Effect of nonlinear hydrodynamic force model on phase trajectories of the towed vessel.

\subsection{Effect of Towline and Tug Motion}

For the autonomous towing system discussed here, the towing forces can be delivered via towline to the towed vessel. Therefore, characteristics such as towline length $\left(L_{T}\right)$, stiffness $(k)$, and configurations are also important parameters which directly affect the towed vessel dynamics. In particular, the towline length is related to the restoring forces in the sway direction, which has an analogy with a typical pendulum system. If the towline length increases, the restoring force in sway direction is reduced, thereby increasing the slewing motion period. Figure 9 shows the phase trajectories of towed vessels with three different towline lengths. It can be seen that as the towline length increases, the overall velocity phase trajectories become smaller with similar shapes. However, as shown in the phase trajectories of $(y, \psi)$, the lateral distance of the sway motion significantly increases with the increase of towline length. For example, when the towline length is the same as the vessel length, the maximum lateral position is about 4.5 times that the vessel breadth. However, when a longer towline, such as one measuring three times the vessel length, is applied, the maximum lateral position increases up to about 6.5 times the vessel breadth. Interestingly, the heading angle is limited to approximately $45^{\circ}$ in this case, and the yaw rate tends to decrease due to the large slewing motion in lateral direction, as shown in the $(\mathrm{v}, \mathrm{r})$ phase trajectory. 


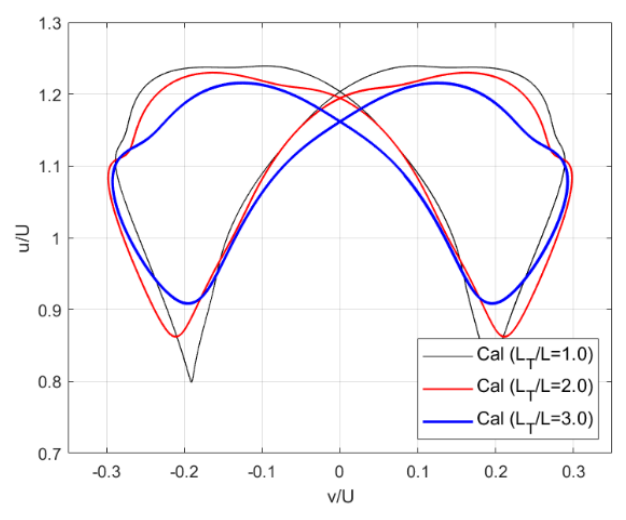

(a) $(\mathrm{u}, \mathrm{v})$ phase trajectory

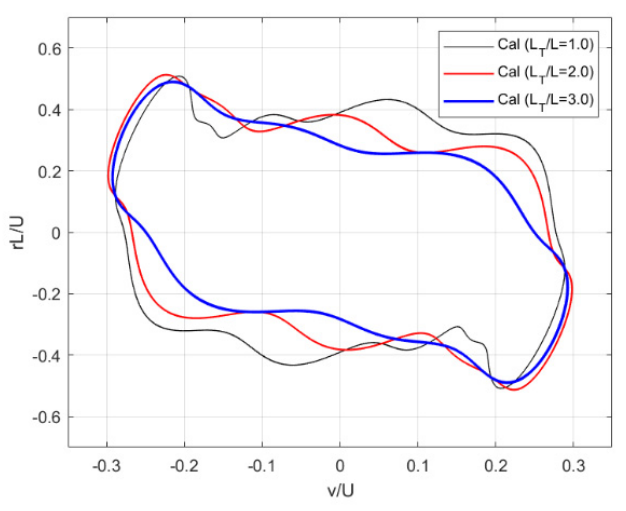

(c) $(\mathrm{v}, \mathrm{r})$ phase trajectory

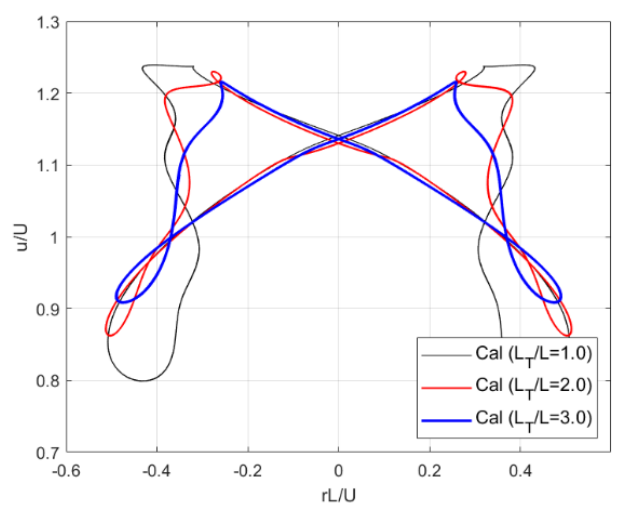

(b) $(\mathrm{u}, \mathrm{r})$ phase trajectory

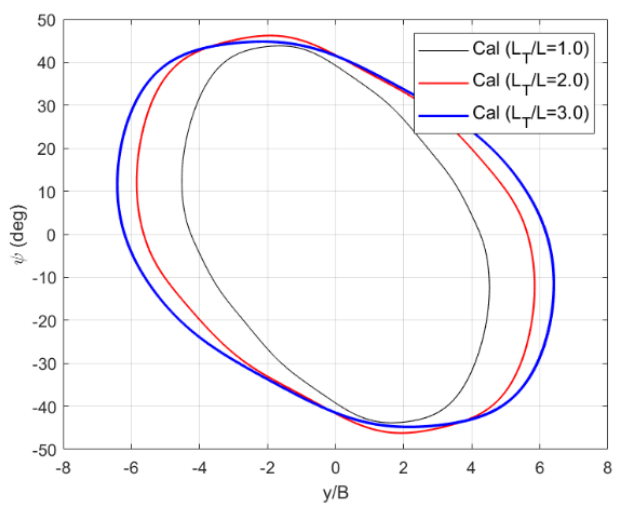

(d) $(y, \psi)$ phase trajectory

Figure 9. Phase trajectories of the towed vessel under various towline conditions $(\mathrm{Fn}=0.145)$.

In real towing operation, towline has a nonlinear stiffness with horizontal catenary configuration. For simplicity, in this study, to check the nonlinear effect of the towline, bilinear towline models were used. Figure 10 compares the dynamic responses of the towed vessel when different bilinear towline models shown in Equation (8) are applied. Here, two spring constants, $k_{1}$ and $k_{2}$ denote the spring constants, when the towline $\left(L_{T}\right)$ is stretched and slacked, compared to the initial unstretched length $\left(L_{T 0}\right)$, respectively.

$$
k= \begin{cases}k_{1} & \text { if } L_{T} \geq L_{T 0} \\ k_{2} & \text { if } L_{T}<L_{T 0}\end{cases}
$$

It is expected that the towline spring will decrease significantly as the towline is slacked. As shown in present numerical simulations, until the stiffness ratio of the towline is bigger than $10 \%$, the limiting cycle is retained, showing almost a single trajectory. However, as the stiffness ratio of the towline becomes about $5 \%$, the trajectories become thicker, meaning that the limiting cycle has a long period. When the stiffness ratio is 0.01 , very complex trajectories can be found. This means that the dynamic characteristics of the towed vessel come closer to being chaotic, due to the nonlinear stiffness effect of the towline.

Up to now, we have neglected the effect of tug motion on the towed vessel dynamics. However, in real situations, the towed vessel and tug motions are fully coupled in the total towing system. In other words, the tug motion can also affect the dynamics of the towing system. In this section, in order to check the tug motion effect on the dynamic characteristics of the towing system, additional simulations, including prescribed tug motion, are discussed. Figure 11 shows the time series of the towed vessel motion considering tug longitudinal disturbances. In this case, the tug motion disturbances are 
assumed to be harmonic motion responses, by applying Equation (9), and the tug motion amplitude $\left(A_{\text {tug }}\right)$ is assumed as $5 \%$ of the towed vessel length.

$$
x_{\text {tug }}=V_{\text {tow }} t+A_{t u g} \cos \left(\omega_{t u g} t\right)
$$

As shown in the figure, the towed vessel exhibits more irregular slewing motion response, due to the tug motion disturbance. In particular, at high frequency condition $\left(\omega_{t u g}(L / g)^{1 / 2}=0.25\right)$, it can be observed that not only slewing motion amplitudes, but also oscillation periods, become more irregular. Figure 12 compares the phase trajectories under the various tug motion frequency conditions. Owing to the tug motion effect, two distinct features are found when comparing with the phase trajectories of no tug motion. First, asymmetric patterns are found, especially when the nondimensionalized oscillation periods $\left(\omega_{t u g}(L / g)^{1 / 2}\right)$ are $0.10,0.15$ and 0.30 . The other feature is the limit cycle of multiple lines, which means that the limiting cycle has much longer periods, especially when the nondimensionalized oscillation periods $\left(\omega_{t u g}(L / g)^{1 / 2}\right)$ are 0.15 and 0.25 .
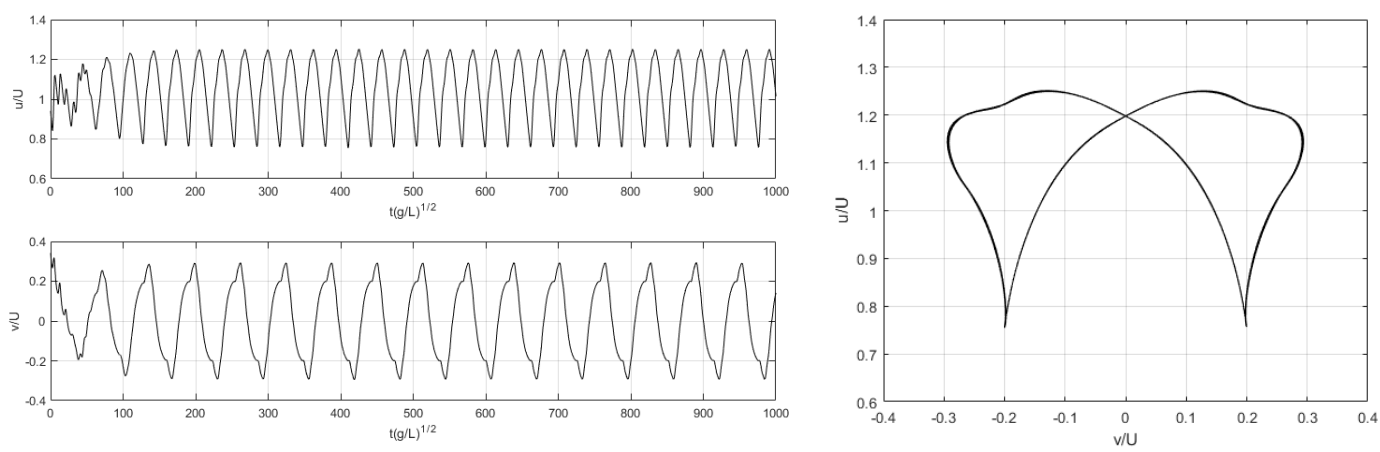

(a) $k_{2} / k_{1}=0.1$
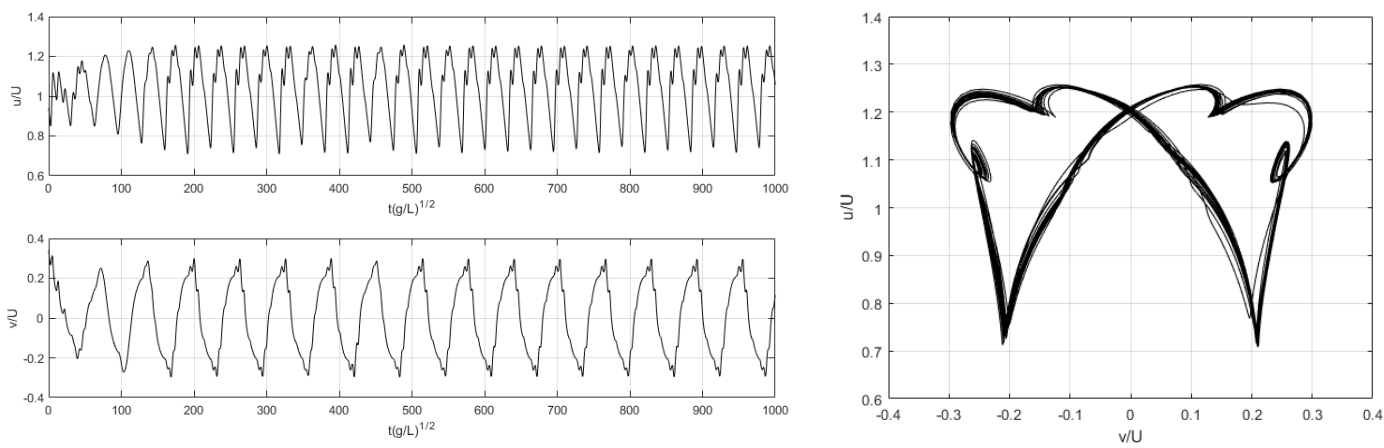

(b) $k_{2} / k_{1}=0.05$
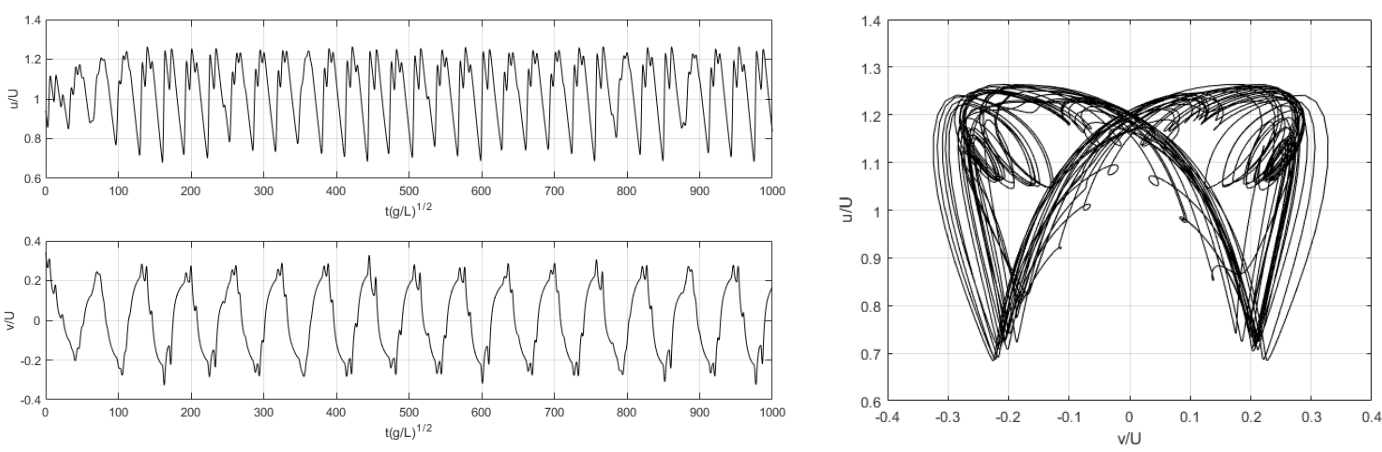

(c) $k_{2} / k_{1}=0.01$

Figure 10. Time series and phase trajectories of the towed vessel with different bilinear towline models. 


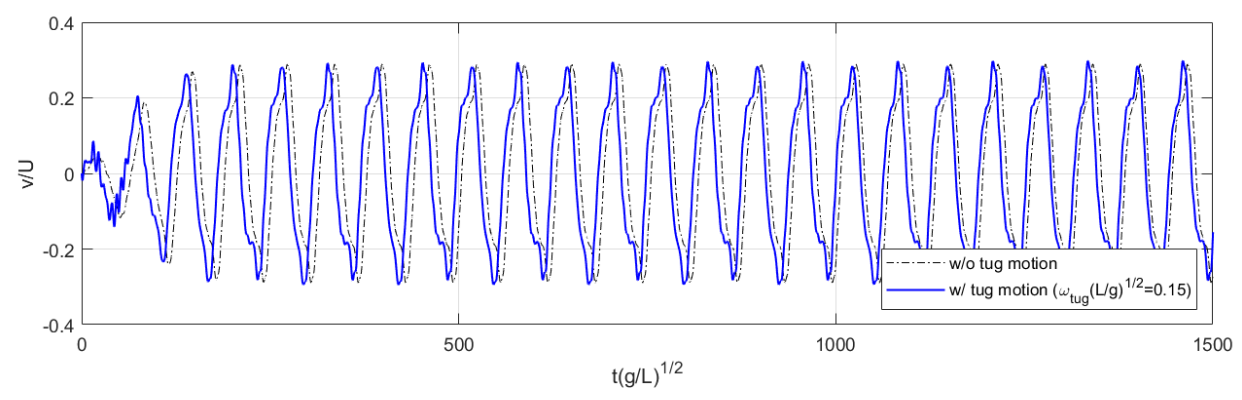

(a) $\omega_{\text {tug }}(L / g)^{1 / 2}=0.15$

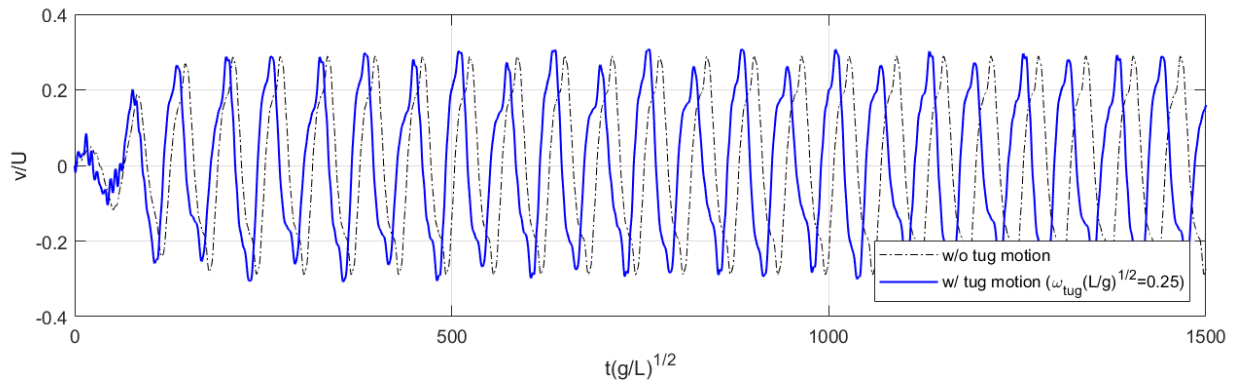

(b) $\omega_{t u g}(L / g)^{1 / 2}=0.25$

Figure 11. Time series of the towed vessel motion with tug longitudinal motions $\left(A_{t u g} / L=0.05\right)$.

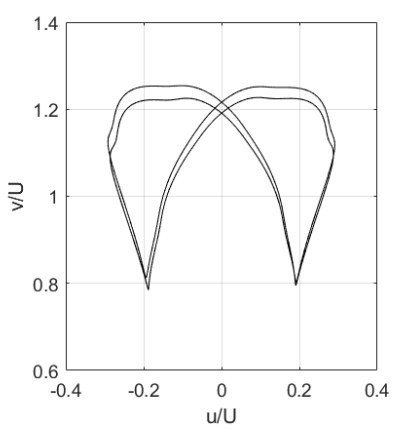

(a) $\omega_{\text {tug }}(L / g)^{1 / 2}=0.05$

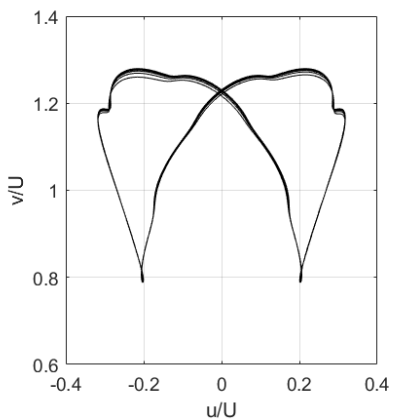

(d) $\omega_{t u g}(L / g)^{1 / 2}=0.20$

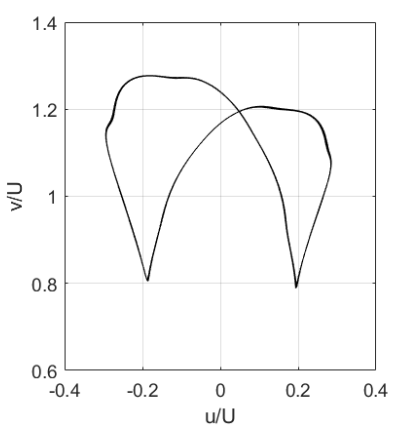

(b) $\omega_{t u g}(L / g)^{1 / 2}=0.10$

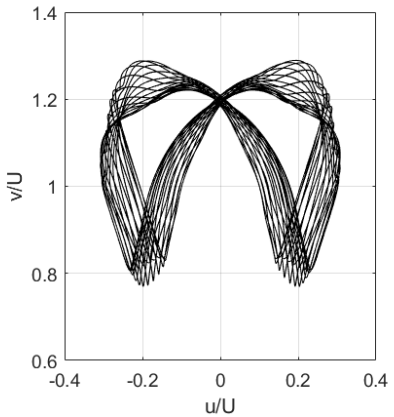

(e) $\omega_{t u g}(L / g)^{1 / 2}=0.25$

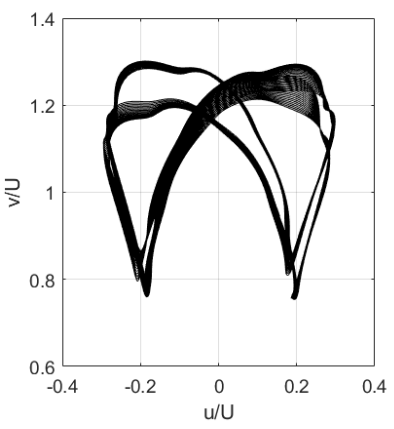

(c) $\omega_{\text {tug }}(L / g)^{1 / 2}=0.15$

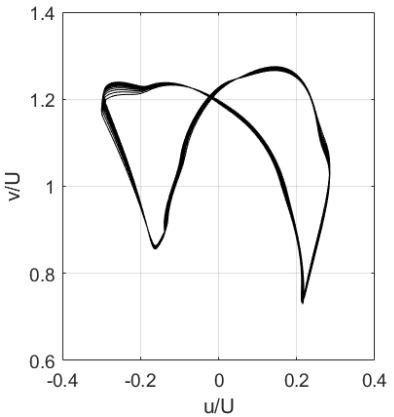

(f) $\omega_{\text {tug }}(L / g)^{1 / 2}=0.30$

Figure 12. Phase trajectories of the towed vessel with considering tug longitudinal motions $\left(A_{\text {tug }} / L=0.05\right)$. 


\section{Conclusions}

In this study, various numerical studies were carried out to investigate the nonlinear dynamic characteristics of an autonomous towing system. The following is a summary of the study, the findings, and the above discussions:

(1) The present simulation results with phase plane analysis demonstrate that the dynamic system of the towed vessel has a stable limit cycle. It can be clearly observed that the dynamic states of the towed vessel are quickly attracted to the same limit cycle within a short time of transient response. The limit cycle shows that the lateral velocity (v) and yaw rate (r) have almost twice the oscillation period of surge velocity $(\mathrm{u})$. In the case of towline tension, high tension peaks occur when the towed vessel changes its heading, at both lateral end positions of the slewing trajectory.

(2) The towing phase trajectories are significantly affected by hull hydrodynamic force coefficients, i.e. hull force models, especially yawing moment and fluid resistance. It can be observed that the phase trajectories become smaller with the decrease of the yawing moment, while the increase of resistance makes the phase trajectories smaller. Regarding the towing speed, it can be confirmed that the limit cycles are not greatly changed under the non-dimensional phase space.

(3) The effects of towline and tug motion are discussed based on simulation results. It is found that the dynamic characteristics of the towed vessel come closer to being chaotic due to the nonlinear stiffness effect of the towline, as well as the tug motion effect.

Funding: This work was supported by the New Faculty Startup Fund from Seoul National University.

Conflicts of Interest: The authors declare no conflict of interest.

\section{References}

1. Strandhagen, A.; Schoenherr, K.; Kobayashi, F. The stability on course of towed ship. Trans. SNAME 1950, $58,32-46$.

2. Abkowitz, M.A. Stability and Motion Control of Ocean Vehicles; The MIT Press: Cambridge, MA, USA, 1972.

3. Bernitsas, M.; Kekridis, N. Simulation and stability of ship towing. Int. Shipbuild. Prog. 1985, 32, 112-123. [CrossRef]

4. Hancox, M. Towing; Clarkson Research Services Ltd.: London, UK, 2011; Available online: https://www. cargotec.com/4a27af/globalassets/files/investors/presentations/cmd-2011-ships-presentation.pdf (accessed on 20 March 2020).

5. Latorre, R. Scale effect in towed barge course stability tests. Ocean Eng. 1988, 15, 305-317. [CrossRef]

6. Yasukawa, H.; Hirata, N.; Nakamura, N.; Matsumoto, Y. Simulations of Slewing Motion of a Towed Ship. J. Jpn. Soc. Nav. Arch. Ocean Eng. 2006, 4, 137-146.

7. Hong, S.Y.; Nam, B.W.; Kim, J.H.; Park, J.Y. A Study on Towing Characteristics of a Transportation Barge in Waves. In Proceedings of the 23th International Offshore and Polar Engineering Conference, Anchorage, AK, USA, 30 June-4 July 2013; Volume 1, pp. 777-783.

8. Fitriadhy, A.; Yasukawa, H. Slewing Motion Characteristics of a Towed Ship in Steady Wind. In Proceedings of the 29th International Conference on Ocean, Offshore and Arctic Engineering, Shanghai, China, 6-11 June 2010; pp. 411-418.

9. Fitriadhy, A.; Yasukawa, H.; Koh, K.K. Course stability of a ship towing system in wind. Ocean Eng. 2013, 64, 135-145. [CrossRef]

10. Fitriadhy, A.; Yasukawa, H. Course Stability of a Ship Towing System. Ship Technol. Res. 2011, 58, 4-23. [CrossRef]

11. Nam, B.W.; Park, J.Y.; Hong, S.Y.; Sung, H.G.; Kim, J.-W. Numerical Simulation of Towing Stability of Barges in Calm Water. J. Ocean Eng. Technol. 2013, 27, 67-73. [CrossRef]

12. Wichers, J.E.W. A Simulation Model for a Single Point Moored Tanker; Maritime Research Institute Netherlands Publication, No. 797: Wageningen, The Netherlands, 1988. Available online: https://pdfs.semanticscholar. org/6b2e/81cf7a443caa12680375765181b0710db014.pdf (accessed on 20 March 2020). 
13. Nam, B.W.; Choi, Y.-M.; Hong, S.Y. A Study on Towing Characteristics of Barge Considering Wind Force. J. Ocean Eng. Technol. 2015, 29, 283-290. [CrossRef]

14. Fitriadhy, A.; Yasukawa, H.; Maimun, A. Theoretical and experimental analysis of a slack towline motion on tug-towed ship during turning. Ocean Eng. 2015, 99, 95-106. [CrossRef] 